\title{
Employment effects for renewable energy industry: A literature review
}

\author{
Yang Chen \\ North China Electric Power University, No.2, Beinong Road, Huilongguan, Changping District, \\ Beijing, China \\ 3045784105@qq.com
}

\begin{abstract}
Keywords: Renewable energy, Employment effect, Estimation methods
\end{abstract}
\begin{abstract}
With the rapid development of renewable energy industry all around the world, a large amount of job opportunities are created. Under this circumstance, lots of scholars are devoted to the researches concerning the employment promoting ability of this new department, and have obtained amount of systematic research fruits. In this paper we present an up-to-date literature review on renewable energy employment effects, and summarize these studies in three aspects: employment types, measurement indexes and calculation methods. Our first conclusion is that employment effects are always divided into 3 types: direct effect, indirect effect and induced effect. The input-output (IO) or computable general equilibrium (CGE) models and spreadsheet-based analytical models are the two most broadly adopted methods to estimate the employment effects of renewable energy. However, these publications cover many different countries, several technology options, and have different assumptions so they present widely varying results derived from distinct methodological approaches. Therefore, at the end of this paper we provide corresponding suggestions and solutions based on the current problems.
\end{abstract}

\section{Introduction}

Energy is a crucial resource which can promote economy, guarantee people's livelihoods, as well as the keystone of maintaining safety of country, stability of macro finance and fulfill sustainable development. However, large scale of exploiting global fossil fuel makes the storage of oil, gas and coal deplete fast. Meanwhile, the combustion of fossil fuel brings about a list of environmental crisis like climate change or ecosystem devastation and so on. Nowadays energy consumption structure has posed a threat to human being's sustainable development. With the governments becoming cognizant of the severity of this problem, many supports are provided to fuel the exploiting of renewable energy. Consequently, in recent few years the renewable energy industry is on the way to boom.

At the same time, the development of renewable energy industry brings up a series of job growth in related industrial chain. Because the renewable energy is an integrated industry, its development will drive up several industries including infrastructures constructing, devices running, small-size set manufacturing, distributional infrastructures service, logistics transporting, researching and developing, management, education and training, consulting, etc. Moreover, employees are required more professional and comprehensive quality. Given that the renewable energy is a high-tech business, a mount of professionals (researchers, architectures, installation personnel, etc.) are necessary, especially the talents for research and management who are equipped with universal knowledge and skills. From this view, the renewable energy industry will contribute to raise overall social employment quality.

In recent years, the employment effects of renewable energy attract more attention in relevant literature and reports but there are radical differences in estimation methods, calibers and results. To better understand this effect, a review and summery about existing studies and researches will be included in this paper. 


\section{Definitions of employment effects for renewable energy industry}

Eva et al. demonstrated the temporary and lasting labor problem. When analyzing the employment effect ratio in manufacturing stage, we usually presume that the labor is temporary, then use "person-year per MW installed" as the unit of measure. In the operation and maintenance and fuel processing stages the ratio "number of jobs per MW installed" is adopted because the number of people that would need to be employed continuously to operate the plant [1].

IRENA straightly defined the direct, indirect and induced employment, which core concepts had a little difference from the existing statement: direct employment is related to core activities of a department, including material supplying, manufacturing, program developing (site preparation and installation), operation and maintaining etc.; indirect employment contains increase of jobs in every relevant investment departments during manufacturing, running and maintaining; inducing employment refers to the jobs provoked by the demand of renewable energy industry, which results from the consumption for the increase of wealth led by renewable energy industry $[2,3]$.

\section{Evaluation on the employment effects of renewable energy industry}

\subsection{Measurement Indexes.}

To measure the employment effects is to measure the change of jobs which caused by a specific economic activity (such as investment, installed capacity, output) or policy. In the actual measurement, there are differences in job nature and employment cycle which raise the needs for a standard treatment of jobs. Only employment effects are calculated by the same unit, can we compare and analyze these figures effectively. So before the definition of the indexes, standardizing the unit of measurement should be tackled first.

Kammen et al. came up with the most common method for standardization: translating different job periods into working years, human years, or full time equivalent (FTE). The basic approach to unity the units is ascertaining a standard annual working time as human year (or working year, or FTE), then comparing the actual working time with the standard time to confirm the workload for a certain job. For example, maintaining one device costs one technician a month, so the workload is 1/12 human year. Utilizing the standardization can calculate and compare jobs in different kinds, techniques, and time spans. In the study of renewable energy employment, due to the various types of wind power, solar power or biomass power, as well as the multiple techniques and eclectic links during manufacturing, installing, operation, it is critical to standardize the quantity in order to compare different industries' employment effects conveniently [4].

The employment effects are focused on the influence of intra industry investment, installed capacity or output on employment quantity. The most important thing is to get the corresponding employment quantity for unit investment, unit installed capacity or unit output. The following three indicators are commonly used:

The employment effect coefficient corresponding to the investment, i.e., the work opportunity created by each million dollars. The research of REPP (2001) found that every million dollars invested on wind power or solar PV can create work opportunity equaling to 5.7 work year. Whereas the figure for coal power can only be 3.9 [5]. REPP (2005) found that every billion investment on wind generator components can create 3000 FTE [6].

The employment effect coefficient corresponding to the output such as opportunity created by each GWh. Wei et al. (2010) was based on this point of view and summarized 15 types of employment effects concerning renewable energy and energy efficient [7].

The employment effect coefficient corresponding to the installed capacity, i.e., opportunity created by each unit of installed capacity. Kammen (2007) summarized 13 types of employment effect from this aspects [4].

Due to the stable quantity relation between producing ability, investment and output, there is a convertible relation between unit cost, capacity factor and output (i.e., the first two can convert to the last one) when we serve installed capacity as estimating index. While the renewable energy industry 
is a fast developing industry, unit cost may decline drastically because of technical progression and scale effect. Thus the investments corresponding to per unit installed capacity will keep changing with cost, leading to a time lag and uncertainty if investment index is adopted. As a conclusion, unless in order to get the effects of investment on employment, it will be more accurate, consequential and scientific if output or installed capacity is adopted [7].

\subsection{Approaches to estimating jobs.}

In the study of relationship of job opportunities and renewable energy, some studies adopted relatively clearer methods such as complex models, industrial investigations, exogenous estimations etc. In general, these studies can be divided into 2 categories from their methods.

The input-output (IO) or computable general equilibrium (CGE) models

In the work report of IRENA, the calculation of input-output model is presented: on the basis of the change of other industries to quantify a change result for the specific industry. Thus it can synthesize each industry in an economical entity and provide the estimated value for renewable energy's employment effect. IO model will provide the net employment effects through the inflow from one department and outflow from the other department. Moreover, it is useful in reflecting the effects of renewable energy development on the overall economy employment, which includes direct, indirect and induced effect. And it also includes the supplanting effect to other departments, namely, the decrease of employment in other departments brought up by the increase of employment in renewable energy [8].

Bernhard Hillebrand evaluated the inflow and outflow of renewable energy employment from two aspects: on the one hand, government subsidy triggers large amount of investment, and the generalization of renewable energy calls for active employment effect; on the other hand, the expenditure for salary and cost produced by fixation of producing, transporting systems leads to passive employment effect. The author adopted a dynamical IO model and counted labor quantity, employed number, average working hours, labor productivity, wages etc. [9].

Grant Allan applied the multi-departments CGE model to quantify the influence of expenditure in renewable energy and employment effects in Scotland. Considering the potential added value during the renewable energy development, the author combined the development multipliers from 2010 to 2020 with the worldwide average employment effects in 2009 and got the employment effects in Scotland when installed capacity was 500MW, 1000MW and 2000MW respectively [10].

The spreadsheet-based analytical models

Eva et. al. indicated that the most important part in this model was the data source, because it directly related to the percentage error of the result. The data mostly comes from energy institutions, companies, guilds, second-hand data sources or market analyzing, of which the guilds usually hold the latest news of an industry. In his study, the whole renewable energy industry was divided into three parts; direct employment effect of each part was calculated separately. He believed the use of renewable energy could have influence not only on employment quantity but also employment quality. The employment quantity could gain from the aggregate employment and the proportion of installed capacity. The employment quality was considered from sites, temporary or stable, and the specialization level, the final result was an index reflecting the quality-quality factor (QF) [1].

E. Llera based on precedent data, to mollify the uncertainty of employment effect ratio, he supposed a new assumption: the growth of scale economy and technology will influence the demand of labor, sometimes enlarges the desire for professional talents, sometimes leads to automation in manufacturing link, which lessens the workload of this link. Besides, the trade equilibrium will affect regional employment. On the basis of this assumption, he took the advantage of previous data (the average employment effect and local installed capacity) and got the aggregate employment in Spanish [11]. 


\section{Suggestions}

In light of the above problems and developing prospects of renewable energy, the following aspects should be paid more attentions when measure and ameliorate the researches for employment effect in the future:

Make efforts to analyze employment effect coefficients more comprehensively. Expansion from direct employment effect coefficient to indirect employment effect coefficient and induced employment effect coefficient should be exercised. Detailed resolution of these coefficients might be implemented in each links. Further affluent technical types, more all-round areas ought to be included in researches.

Based on the various status quo of countries and areas, more concrete and practical data may be gained, instead of rough estimations on the basis of preceding studies. It will be better to apply the macroeconomic analysis model or employment effect analytical model which can meet the local characteristics. If existing methods or datum are used, researchers must take care of the circumstances and applicable conditions to guarantee a scientific estimation.

\section{References}

[1] Eva Llera Sastresa, Alfonso Aranda Uso, Ignacio Zabalza Bribia, Sabina Scarpellini. Local impact of renewables on employment: Assessment methodology and case study. Renewable and Sustainable Energy Reviews, Vol. 14 (2010), p. 679-690.

[2] The International Renewable Energy Agency (IRENA). Renewable Energy and Jobs Annual Review (2016).

[3] IRENA. Renewable Energy Policy for Wind Power (2012).

[4] Kammen, Daniel. Green Jobs Created by Global Warming Initiatives ( 2007 ).

[5] Renewable Energy Policy Project (REPP). The Work That Goes into Renewable Energy, Research Report No. 13 (2001).

[6] REPP. Component Manufacturing: Ohio's Future in the Renewable Energy Industry, Technical Report (2005).

[7] Max Wei, Shana Patadia, Daniel M. Kammen. Putting Renewables and Energy Efficiency to Work: How Many Jobs can the Clean Energy Industry Generate in the US?. Energy Policy Vol.38 (2010), p. 919-931.

[8] IRENA. Renewable Energy and Jobs - Annual Review 2015.

[9] Bernhard Hillebrand, Hans Georg Buttermann, Jean Marc Behringer, Michaela Bleuel. The expansion of renewable energies and employment effects in Germany. Energy Policy, Vol. 34 (2006), p. 3484-3494.

[10] Allan G, Gilmartin M. The regional employment impacts of renewable energy expenditures: The case for modelling. Sire Discussion Papers, 2011.

[11] E. Llera, S. Scarpellini, A. Aranda, I. Zabalza. Forecasting job creation from renewable energy deployment through a value-chain approach. Renewable and Sustainable Energy Reviews, Vol. 21 (2013), p. 262-271. 